\title{
Research Article \\ Optimal Placement of Passive Energy Dissipation Devices by Genetic Algorithms
}

\author{
Ji-ting $\mathbf{Q u}{ }^{1,2}$ and Hong-nan $\mathbf{L i}^{3}$ \\ ${ }^{1}$ Faculty of Infrastructure Engineering, Dalian University of Technology, Dalian, Liaoning 116024, China \\ 2 State Key Laboratory of Structural Analysis for Industrial Equipment, Dalian University of Technology, \\ Dalian, Liaoning 116024, China \\ ${ }^{3}$ State Key Laboratory of Costal and Offshore Engineering, Dalian University of Technology, Dalian, \\ Liaoning 116024, China
}

Correspondence should be addressed to Ji-ting Qu, qjt@dlut.edu.cn

Received 5 October 2012; Accepted 23 November 2012

Academic Editor: Fei Kang

Copyright (C) 2012 J.-t. Qu and H.-n. Li. This is an open access article distributed under the Creative Commons Attribution License, which permits unrestricted use, distribution, and reproduction in any medium, provided the original work is properly cited.

\begin{abstract}
A mathematical model is proposed in this paper for locating optimal positions for passive energy dissipative dampers. Three control indices of structural responses with the storey-drift angle, storey displacement, and acceleration are taken in this model. Firstly, six combination modes of these indices are presented. On the premise that the number of dampers is fixed, this paper deals with the optimal placement of two types of passive dampers for several building models with different number of storeys and seismic ground motions at four types of sites using genetic algorithm. Secondly, two estimating indices are presented to assess the reasonable combination mode of coefficients under different conditions, which can generally express the best response control. Numerical examples are illustrated to verify the effectiveness and feasibility of the proposed mathematical model. At last, several significant conclusions are given based on numerical results.
\end{abstract}

\section{Introduction}

The technique of energy dissipation belongs to a kind of passive structural control. The basic role of passive energy dissipation devices is to absorb or consume a portion of the input energy from earthquake or wind, reduce the structural response, and protect structural members. These devices are classified as displacement-based and velocity-based dampers in the China Seismic Code. Among them, metallic yielding damper (MD) and friction damper are the most wildly used displacement-based devices, and their force-deformation responses only depend on the relative displacement between each end of device. They could be 
effective on energy dissipation only if slip displacement is reached. Viscoelastic and viscous dampers are the two typically used velocity-based devices. The viscoelastic damper (VED) dissipates vibration energy when viscoelastic material is subjected to shear deformation, thereby reducing the structural response. These devices are applied in seismic control of buildings broadly because they rarely need to be repaired after being installed and have economical and simple conformation performance.

It is well known that the installation of dampers will reduce seismic responses of structures. To design a structure with energy dissipation devices, the optimal locations of devices will have a significant effect on reducing responses and achieving desired design objectives. Commonly, it may be convenient to distribute the devices to every storey or one storey interval. However, such a placement may be uneconomical and not be the most effective means because installation of dampers may increase the stiffness of corresponding storey and enlarge responses of neighboring stories. Therefore, the research of optimal design causes designers' interest.

In the past decades, many researchers have contributed themselves to studies on the optimal location of dampers in structures. Haftka and Adelman [1] had a study on selection of actuator locations in large space structures based on worst out in and exhaustive singlepoint substitution methods. However, this technique leads to a locally optimal solution near the starting design guess. Ashour and Hanson [2] suggested placing devices on locations that would maximize the damping ratio of the fundamental mode because of its dominance in multistorey buildings' mode. Zhang and Soong [3] used a simplified sequential search algorithm to determine the optimal location of VEDs in an unsymmetrical shear building. Parametric and positioning optimization analyses about VEDs were conducted by Gürgöze and Müller [4] for a linear multi-degree-of-freedom structure. Several other methods were adopted for location optimization, such as topological approach suggested by Natke and Soong [5], simulated annealing optimization used by Milman and Chu [6], and others by Takewaki [7] and Takewaki et al. [8] made use of a gradient-based method to search for optimal locations. According to the capability and characteristic of structures with VEDs, Zhou et al. [9] proposed five different optimum design methods for installation of dampers and analyzed an example of a ten-floor reinforced concrete structure. Zhang et al. [10] suggested a convenient and practical methodology about choosing parameters and locations of VEDs, and effects of controlling of structural vibration for different positions of these devices were compared. In practical applications, the location variables are discrete as the numbers of dampers are fixed. Theoretically, the optimal solution of such a discrete problem can be obtained by an enumerative search of every possible combination of dampers' position. In fact, the number of feasible locations is too large. Thus, a versatile and flexible method called genetic algorithm was suggested especially for problems whose performance index is not a continuous function when the design variable and the variable design space are discrete [11-13]. Singh and Moreschi [14] utilized this approach to study the layout and parametric optimization of viscous and viscoelastic dampers to achieve a desired performance. Moreschi and Singh [15] presented a methodology to determine the optimal design parameters for the yielding metallic and friction devices installed at different locations in a building for a desired performance objective. An optimal installation method of MR dampers using genetic algorithms was put forward in order to reduce the vibration response of high-rise building under wind load [16]. Bei and Li [17] gave a new method of improved genetic algorithm and quadratic performance index. Five optimal methods were used to determine the number and location of the magnetorheological dampers in the structure, and several principles were pointed out. 
As displacement-based energy dissipative devices present highly nonlinear characteristics, the installation of such dampers in a structure will render it to behave nonlinearly even if all other structural members are designed to remain linear. Thus, the analysis of structures with these devices must be done by a step-by-step time history analysis. Investigations on optimal placement of displacement-based dampers are not enough and mainly focus on parametrical optimization. Besides, there are two aspects of shortage [18] needed to be improved on location optimization of dampers: on one hand, the objective functions suggested by different scholars are diverse, thus the optimal results are different which can confuse the designers; on the other hand, the investigations all aim at a given structure subjected to one earthquake record. Optimal solutions may change for different structures subjected to various earthquakes. The optimal results derived from one certain earthquake record may be unsatisfied for another record.

The main objective of this research is to study the optimal objective functions of two types of passive energy dissipation devices with fixed numbers. A new mathematic model of location optimization will be established, which is suitable for different kinds of passive dampers. Three seismic response performance indices are taken in this model. To achieve the optimal coefficients of storey-drift angle, acceleration, and storey-displacement indices, this paper deals with the optimal location of two types of passive dampers for several building models with different number of storeys and ground motions at four types of sites. Numerical analyses are illustrated to verify effective and feasibility of the model for optimal locations of dampers and structural control, in which a genetic algorithm is used.

\section{Analytical Modeling of Passive Energy Dissipation Devices}

\subsection{Model of Force-Deformation Relation}

The displacement-based devices are installed in series with bracings at the interstorey of structures. The force-deformation model has often been expressed by the bilinear model. The model of yielding metallic dampers is shown in Figure 1(a), and elastic-perfectly-plastic model is used to approximate friction dampers' model. The combination of a damper and the bracings is called as the device-brace assembly, and its force is represented as $g_{d b}(x)$. The stiffness of assembly can be expressed as

$$
k_{d b 0}=\frac{k_{d 0} k_{b}}{k_{d 0}+k_{b}}, \quad k_{d b 1}=\frac{k_{d 1} k_{b}}{k_{d 1}+k_{b}}
$$

where $k_{d b 0}$ and $k_{d b 1}$ represent the initialized stiffness and the second stiffness of the assembly; $k_{d 0}$ and $k_{d 1}$ represent the initialized stiffness and the second stiffness of dampers.

The combinational stiffness of assembly for friction dampers can be given by

$$
k_{d b 0}=k_{b}, \quad k_{d b 1}=0 .
$$

A number of models of VED with the force-deformation relation have been brought forward, and they are applicable to different conditions. The equivalent stiffness and damping model [19] are here adopted for its wide and simple application. The hysteretic 


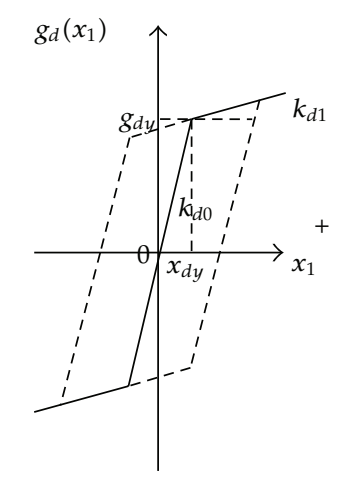

(a) Yielding device

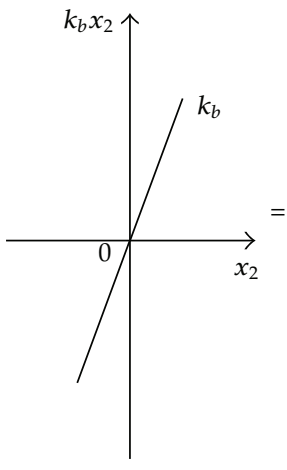

(b) Bracing

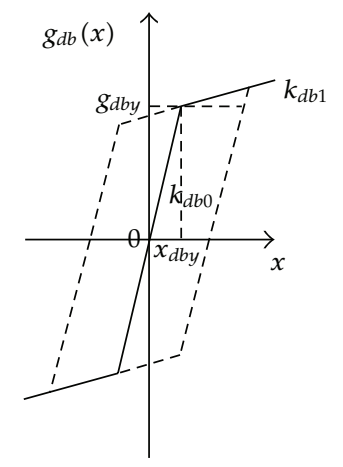

(c) Yielding element

Figure 1: Force-deformation model of yielding metallic dissipation device.

loop of this model is shown in Figure 2. The general formula for the resistance force $F_{v}$ takes the following form:

$$
F_{v}=c_{v}(\omega) \dot{u}+k_{v}(\omega) u
$$

where $c_{v}(\omega)$ and $k_{v}(\omega)$ represent the frequency-dependent damping and stiffness coefficients for the dampers, and they can be determined by

$$
\begin{gathered}
c_{v}(\omega)=\frac{\eta(\omega) G^{\prime}(\omega) A}{\omega \delta}, \quad k_{v}(\omega)=\frac{G^{\prime}(\omega) A}{\delta}, \\
\eta(\omega)=\frac{G^{\prime \prime}(\omega)}{G^{\prime}(\omega)},
\end{gathered}
$$

where $G^{\prime}$ and $G^{\prime \prime}$ are defined as the shear storage modulus and the shear loss modulus of the VE material, respectively; $A$ represents the area of VE material; $\delta$ means the thickness of the VE material; $\eta(\omega)$ is the loss factor that provides a measure of the energy dissipation capability of the VE material; $\omega$ corresponds to the frequency at which these properties are determined.

\subsection{System Equations of Controlled Structure}

The equation of motion for an $\mathrm{N}$-degree-freedom structure with displacement-based energy dissipation devices subjected to earthquake can be written by

$$
[M][\ddot{X}]+[C][\dot{X}]+[g(x, \dot{x})]+\left[g_{d b}(x)\right]=-[M]\left[\ddot{X}_{g}\right]
$$

where $[M]$ and $[C]$ mean the $N \times N$ mass and inherent damping matrices of the structure, $[X]$ is the $N$-dimensional relative displacement vector with respect to the base, $[\dot{X}]$ and $[\ddot{X}]$ are relative velocity and acceleration vector of $N$-dimension, $\left[\ddot{X}_{g}\right]$ implies the seismic excitation, 


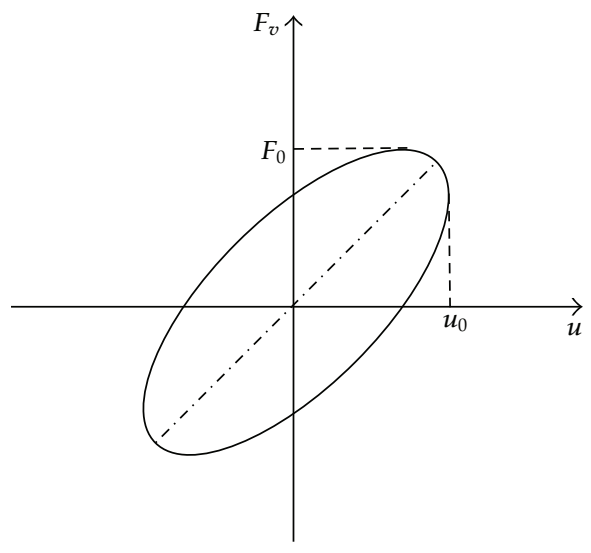

Figure 2: Force-deformation model of VED.

$[g(x, \dot{x})]$ represents force matrix of structure, which depends on the structural force-deformation relationship model; $\left[g_{d b}(x)\right]$ denotes force matrix of device-bracing assembly, which can be determined by hysteretic model of energy dissipation devices.

The equation of motion for an $N$ degree of freedom structure with VEDs subjected to earthquake motion can be written by

$$
[M][\ddot{u}(t)]+\left(\left[C_{s}\right]+\left[C_{v}\right]\right)[\dot{u}(t)]+\left(\left[K_{s}\right]+\left[K_{v}\right]\right)[u(t)]=-[M][I]\left[\ddot{u}_{g}(t)\right],
$$

where $[M],\left[C_{s}\right]$, and $\left[K_{s}\right]$ represent the $N \times N$ mass, inherent damping, and stiffness matrices of structure, $[\ddot{u}(t)],[\dot{u}(t)]$ and $[u(t)]$ are the relative acceleration, velocity, and displacement vectors of $N$-dimension, respectively, $\left[\ddot{u}_{g}(t)\right]$ is the seismic excitation at the base of structure, and $\left[C_{v}\right]$ and $\left[K_{v}\right]$ denote the added damping and stiffness matrices of the VEDs.

\section{Optimization Based on Genetic Algorithm}

\subsection{Genetic Algorithm}

The genetic algorithm (GA) was proposed firstly by professor Holland in 1975 and is a globally optimal and self-adaptive searching method of probability, which is based on principles of "survival of the fittest" and adaptation of biology in nature [20]. GA is effective for optimal questions especially for discrete variables and space, whereas traditional math methods are disabled or hard to resolve [21]. An essential characteristic of the GA is the coding of variables that describe the problem. The most common coding method is to transform the variables to a binary string of specific length, and fitness function is provided to measure the fitness of individual. In GA, a generation of population undergoes successive evolution into future generations through the repeated use of genetic operators, containing reproduction operator, crossover operator, and mutation operator [22-25]. As a new population is created, the performance index is evaluated for each new design to determine its fitness with respect to other designs in the population, until no further 
improvement is observed in the best individual in the subsequent generations, and the optimal solution is obtained.

\subsection{Objective Function}

To bring forward an objective function is a core in optimal design. To design a structure with energy dissipation devices, the optimal location of dampers can make the performance indices be restricted within desired objectives as the number of dampers is fixed. The optimal solutions are often diverse when the optimization formulations are different. For example, if the acceleration control is considered as the performance index, the optimal location of dampers can give a better limit for the acceleration. In the literature, several optimization formulations were proposed with different indices as follows [10]: (1) the largest relative displacement of interstorey; (2) storey-displacement and relative displacement of interstorey; (3) relative displacement of interstorey and the displacement of the peak storey.

These indices all focus on the deformation of structures, which should not be regarded as the only index to be reduced especially for high rise. It is a crucial problem to put forward an optimization formulation considering different indices of seismic response and confirm the combination of coefficients for all the indices.

The aim of seismic control of structures is to make structures safe and comfortable in accord with the Codes. Three indices with the storey-drift angle, acceleration, and storey displacement can reflect the two aspects of structural performance. Thus, a new objective function of optimal location is presented in this paper, expressed as a linear combination of three nondimensional items, considering both security and coziness. In order to avoid the optimal solution applicable only to the special earthquake excitation, three seismic records are used for every kind of site in the step-by-step time history analysis. The optimization formulation can be written in the following form:

$$
\min Z=\alpha \frac{\theta_{\max }}{\theta_{0, \max }}+\beta \frac{a_{\max }}{a_{0, \max }}+\gamma \frac{u_{\max }}{u_{0, \max }}
$$

where $\theta_{\max }$ and $\theta_{0, \max }$ mean the largest storey-drift angles of structure with and without additional energy dissipation devices, $u_{\max }$ and $u_{0, \max }$ are the largest displacements of structure with and without devices, $a_{\max }$ and $a_{0, \max }$ represent the largest accelerations of structure with and without devices and, $\alpha, \beta$, and $\gamma$ denote the weight coefficients, respectively, which have different values according to the demand of application in engineering. The combination of the three weight coefficients is given in detail in Section 4.3.

\subsection{Optimal Variables}

In the context of the problem of optimal location of dampers using GA, optimal variables need to be confirmed. They are expressed as a matrix of position $P$ consisting of 0 and 1 , which indicates locating a damper if the number is one. Premising a determinate number of dampers, the optimal variable shows different positions of number 1 and 0 . The dimension of the positional matrix is determined by the storey number of a structure. For example, if dampers are located one at the second, third and forth floor of a 6-storey structure, respectively, the matrix of position can be written as follow: $P=\left[\begin{array}{llllll}0 & 1 & 1 & 1 & 0 & 0\end{array}\right]$. 


\subsection{Estimating Indices for Combination Modes of Coefficients}

For different form of buildings with different number of storeys and ground motions at four types of sites, the optimal results about six kinds of combination modes of coefficients may be different. In order to compare these modes with another one to decide which one can generate better control of the structures with optimal location of dampers, two estimating dimensionless indices are proposed, which can be denoted as

$$
J_{1}=\frac{1}{n} \sum_{i=1}^{n}\left(\frac{\theta_{i, \max }}{\theta_{0, i, \max }}\right)^{2}, \quad J_{2}=\frac{1}{n} \sum_{i=1}^{n}\left(\frac{a_{i, \max }}{a_{0, i, \max }}\right)^{2},
$$

where $\theta_{i, \max }$ and $\theta_{0, i, \max }$ imply the mean values of largest storey-drift angle of structures with and without dampers for the $i$ th floor, $a_{i, \max }$ and $a_{0, i, \max }$ represent the mean values of largest accelerations of structures with and without the devices, respectively. $J_{1}$ and $J_{2}$ all take responses of each floor into consideration, which can reflect the response control in general. For six combination modes of coefficients, the two indices should be calculated, respectively, for different buildings with optimal located dampers. The smaller the values of the indices are, the better the combination mode is.

\subsection{Optimal Design Process Based on Genetic Algorithms}

(1) Confirm decision-making variables and conditions of restriction, and create a stochastic initial population $P_{0}$.

(2) Optimal formulation is established; namely, confirm the type of objective function (determine the maximum or the minimum value of the objective function).

(3) Design genetic operators, such as select, crossover, and mutation operators.

(4) Make certain related parameters of GA, containing the number of population $(M)$, the terminate generation of genetic operation $(T)$, probability of crossover $\left(p_{c}\right)$, and probability of mutation $\left(p_{m}\right)$.

(5) Do step-by-step time history analysis of system by inputting records of earthquakes, and compute the value of the objective function associated with the satisfied solution to get the optimal placement of supplemental dampers.

The system analysis and location optimization procedures are programmed by adopting MATLAB programming language. Figure 3 illustrates the optimal design flow chart.

\section{Numerical Analyses}

In order to realize the optimal locations to diverse structures at different types of sites, three structures with low, moderate, and high rise height are chosen separately here. The positional optimization of displacement-based energy dissipative devices (MD is considered) and velocity-based devices (VEDs are considered) is processed according to four-site condition. For each type of site, three earthquake records are selected having the close period with the characteristic period of corresponding site. The parameters of GA are taken as follows. The terminate generation of genetic operation is 300 . The probabilities of crossover and mutation are 0.8 and 0.2 , respectively. 


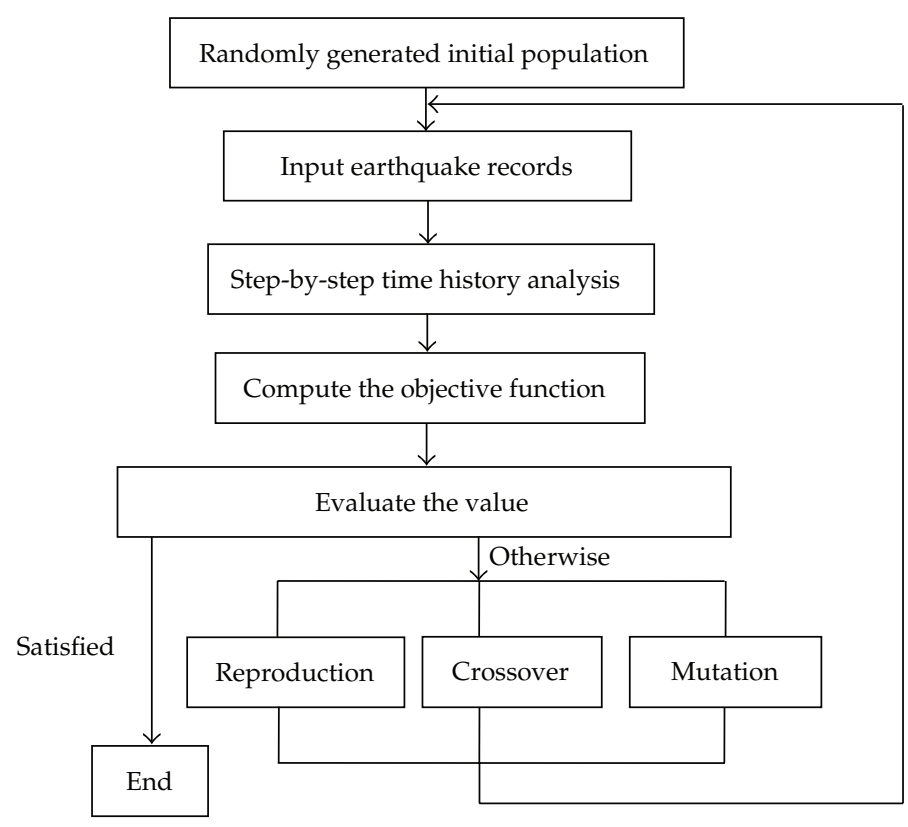

Figure 3: Optimal design flow chart.

\subsection{Building Models and Parameters of Dampers}

\section{Building 1.}

A 5-storey shear building has uniform properties along its height. The mass is $2.0 \times 10^{5} \mathrm{~kg}$, the story stiffness is $4.2 \times 10^{8} \mathrm{~N} / \mathrm{m}$, and the height for each story is $3.3 \mathrm{~m}$. The damping ratio is taken as $5 \%$, and the period of structure is obtained with $0.4817 \mathrm{~s}$. 3 VEDs or MDs will be installed on the structure.

\section{Building 2 (see [9]).}

A 10-storey shear building is considered. The mechanical properties of this building are depicted in Table 1 . The damping ratio is $5 \%$ and period of structure is $1.4583 \mathrm{~s}$. 6 VEDs or MDs are chosen to be placed.

\section{Building 3 (see [26]).}

The third structure is a 16-storey shear building. Its mechanical properties are provided in Table 2 . The damping ratio is $5 \%$, and period of structure is $2.3848 \mathrm{~s}$. According to the formula of effective damping ratio attached by energy dissipation in China Seismic Code, seventy-two VEDs will provide the same effective damping ratio as nine MDs do. So 9 MDs or 72 VEDs are chosen to be installed.

The typical VED with two viscoelastic layers is designed, where $G^{\prime}=1.5 \times 10^{7} \mathrm{~N} / \mathrm{m}^{2}$, $G^{\prime \prime}=2.01 \times 10^{7} \mathrm{~N} / \mathrm{m}^{2}, A_{s}=3 \times 10^{-2} \mathrm{~m}^{2}$, and $\delta=1.3 \times 10^{-2} \mathrm{~m}$. The working temperature is $25^{\circ} \mathrm{C}$. Three initial stiffness of the device-bracing assembly installed on three buildings are 
Table 1: Mechanical properties of 10-storey building.

\begin{tabular}{lccc}
\hline Floor & Mass $(\mathrm{kg})$ & Highness $(\mathrm{m})$ & Stiffness $\left(\mathrm{N} \times \mathrm{m}^{-1}\right)$ \\
\hline 1 & $1.52 \times 10^{6}$ & & $2 \times 10^{9}$ \\
2 & $1.52 \times 10^{6}$ & & $1 \times 10^{9}$ \\
3 & $1.349 \times 10^{6}$ & 3.0 & $1.43 \times 10^{9}$ \\
4 & $1.349 \times 10^{6}$ & & $1.11 \times 10^{9}$ \\
5 & $1.349 \times 10^{6}$ & & $1 \times 10^{9}$ \\
$6-9$ & $1.349 \times 10^{6}$ & & $0.769 \times 10^{9}$ \\
10 & $1.187 \times 10^{6}$ & $0.417 \times 10^{9}$ \\
\hline
\end{tabular}

Table 2: Mechanical properties of 16-storey building.

\begin{tabular}{lccc}
\hline Floor & Mass $(\mathrm{kg})$ & Highness $(\mathrm{m})$ & Stiffness $\left(\mathrm{N} \times \mathrm{m}^{-1}\right)$ \\
\hline 1 & $4.84 \times 10^{6}$ & 3.6 & $5.1 \times 10^{9}$ \\
2 & $4.67 \times 10^{6}$ & 3.0 & $3.6 \times 10^{9}$ \\
3 & $4.35 \times 10^{6}$ & 3.0 & $3.8 \times 10^{9}$ \\
4 & $4.31 \times 10^{6}$ & 3.0 & $3.21 \times 10^{9}$ \\
$5-9$ & $4.07 \times 10^{6}$ & 3.0 & $2.54 \times 10^{9}$ \\
$10-13$ & $3.81 \times 10^{6}$ & 3.0 & $2.13 \times 10^{9}$ \\
$14-16$ & $3.57 \times 10^{6}$ & 3.0 & $1.92 \times 10^{9}$ \\
\hline
\end{tabular}

Table 3: Earthquake records.

\begin{tabular}{ccccccc}
\hline Site & Group & Records & Component & $\begin{array}{c}\text { Interval } \\
(\mathrm{s})\end{array}$ & $\begin{array}{c}\text { Time } \\
(\mathrm{s})\end{array}$ & $\begin{array}{c}\text { Peak } \\
\text { value } \\
\left(\mathrm{cm}^{2} \mathrm{~s}^{2}\right)\end{array}$ \\
\hline & F1 & 1985, La Union, Michoacan Mexico & N00E & 0.01 & 62.71 & 162.79 \\
I & F2 & 1994, Los Angeles Griffith Observation, Northridge & 360 & 0.005 & 28.75 & 163.80 \\
& N1 & 1988, Zhutang, A, Langcang & S00E & 0.01 & 25.32 & 541.60 \\
& F3 & 1971, Castaic Old bridge Route, San Fernando & N69W & 0.02 & 61.87 & 265.40 \\
II & F4 & 1979, El Centro, Array no. 10, Imperial valley & N69W & 0.01 & 37.07 & 168.21 \\
& N2 & 1988, Gengma Gengma1 & S00E & 0.02 & 12.36 & 140.75 \\
& F6 & 1984, Coyote Lake Dam, Morgan Hill & 285 & 0.02 & 59.98 & 1137.80 \\
III & F7 & 1940, El Centro-Imp Vall Irr Dist, El Centro & 270 & 0.02 & 53.47 & 210.10 \\
& N3 & 1988, Gengma Gengma 2 & S00E & 0.02 & 16.56 & 90.02 \\
& F8 & 1949, Olympia Hwy Test Lab, Western Washington & 356 & 0.02 & 89.16 & 161.63 \\
IV & F9 & 1981, Westmor and, Westmoreland & 90 & 0.02 & 88.43 & 353.97 \\
& N4 & 1976, Tianjin Hospital, Tangshan & WE & 0.01 & 19.19 & 104.18 \\
\hline
\end{tabular}

$2.928 \times 10^{8} \mathrm{~N} / \mathrm{m}, 1.64 \times 10^{8} \mathrm{~N} / \mathrm{m}$, and $8 \times 10^{8} \mathrm{~N} / \mathrm{m}$. The yield deformation of dampers is taken as $4 \mathrm{~mm}$.

\subsection{Earthquake Records}

Different earthquake records, even though similar intensities, lead to widely varying responses, and results based on a single record may not be conclusive. Here, twelve earthquake records are chosen [26] and three for each type of site are shown in Table 3. The values of peak ground accelerations are scaled to 400 gal. 
Table 4: Combination modes of optimal coefficients.

\begin{tabular}{|c|c|c|c|c|}
\hline Mode & $\alpha$ & $\beta$ & $r$ & Objective of optimization \\
\hline 1 & 1 & 0 & 0 & Considering storey-drift angle only, namely, security \\
\hline 2 & 0.7 & 0.1 & 0.2 & $\begin{array}{l}\text { Taking storey-drift angle as the main factor, acceleration, and storey } \\
\text { displacement as additive factors. }\end{array}$ \\
\hline 3 & 0.5 & 0.3 & 0.2 & Considering the weight of storey-drift angle as half of the importance \\
\hline 4 & 0.1 & 0.7 & 0.2 & Considering acceleration as the main factor \\
\hline 5 & 0 & 1 & 0 & Considering acceleration only, namely, amenity \\
\hline 6 & 0.5 & 0.5 & 0 & Considering only storey drift to reflect deformation of the structure \\
\hline
\end{tabular}

Table 5: Location optimization of MDs for 5-storey building.

\begin{tabular}{lcccc}
\hline Site & Modes 1 and 2 & Mode 3 & Modes 4 and 5 & Mode 6 \\
\hline I & 123 & 123 & 124 & 124 \\
II & 123 & 123 & 123 & 123 \\
III & 123 & 123 & 125 & 125 \\
IV & 123 & 125 & $125 / 135$ & 125 \\
\hline
\end{tabular}

Annotation: the numbers in the table represent the floor of optimal location. For example, number 1 and 2 mean that dampers are positioned at the first and the second floor of the building.

Table 6: Location optimization of MDs for 10-storey building.

\begin{tabular}{lcccc}
\hline Site & Modes 1 and 2 & Mode 3 & Modes 4 and 5 & Mode 6 \\
\hline I & 2456710 & 2567810 & 2678910 & 125689 \\
II & 125679 & 1256710 & 1267810 & 1256710 \\
III & 123467 & 1256710 & 1267910 & 123567 \\
IV & 234567 & 123456 & 123456 & 2567810 \\
\hline
\end{tabular}

Table 7: Location optimization of VEDs for 10-storey building.

\begin{tabular}{lcccc}
\hline Site & Modes 1 and 2 & Mode 3 & Modes 4 and 5 & Mode 6 \\
\hline I & 2678910 & 2678910 & 5678910 & 2678910 \\
II & 125678 & 2567810 & 2678910 & 2678910 \\
III & 2456710 & 2456710 & 2678910 & 2567810 \\
IV & 234567 & 245678 & 2567810 & 2567810 \\
\hline
\end{tabular}

\subsection{Combination of Coefficients in Optimal Function}

In order to confirm the value of weight numbers $\alpha, \beta$, and $\gamma$ preliminarily, the calculation of coefficient values is done. When $\alpha$ values are taken from 0.8 1, 0.6 0.8, and 0.3 0.6, the optimal results are almost the same. Consequently, six kinds of combination modes are proposed considering $\alpha$ as the main factors shown in Table 4.

\subsection{Optimal Results}

Utilizing the above combination modes of coefficients in the objective function, the location optimizations of two types of dampers for three structures at four types of sites are done. 


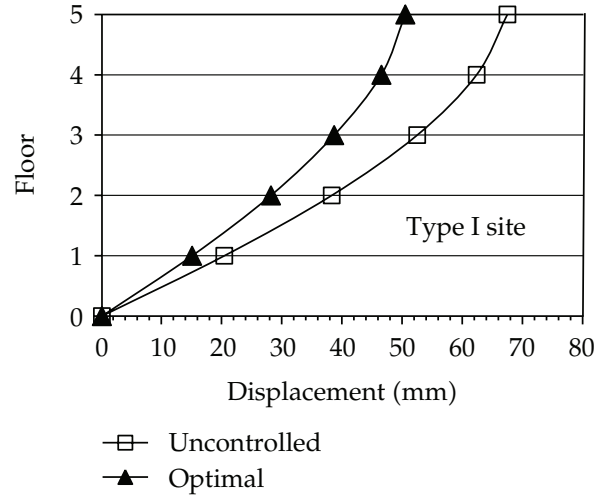

(a)

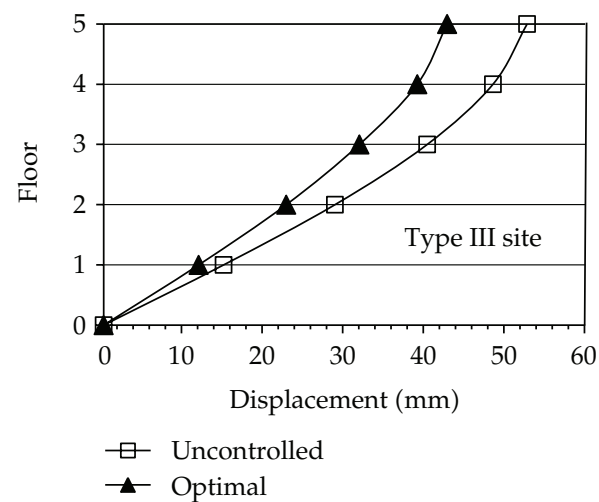

(c)

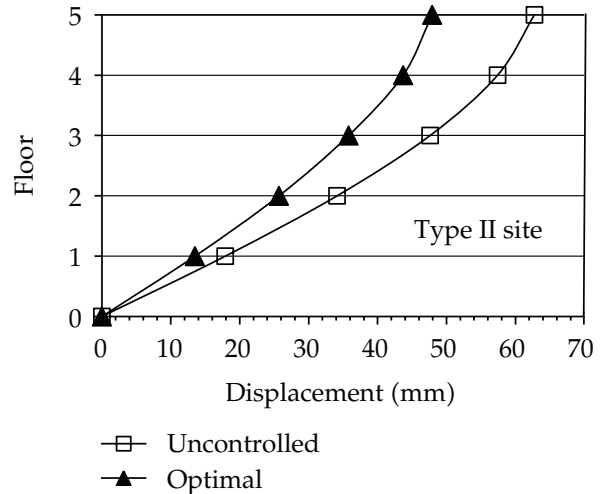

(b)

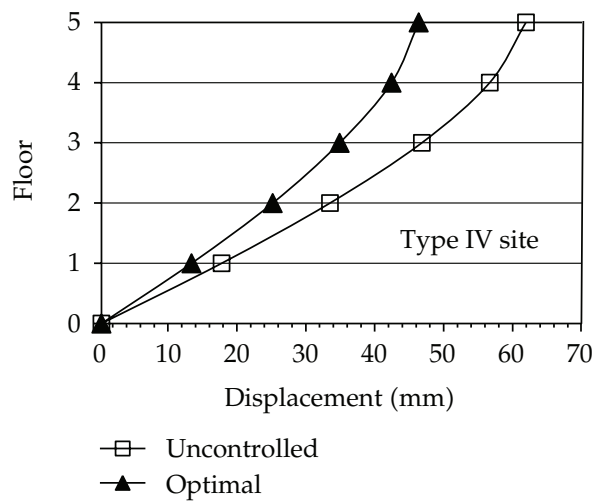

(d)

Figure 4: Envelope diagrams of maximal displacement for 5-storey structure with VEDs.

\subsubsection{5-Storey Building}

The optimal results of VEDs are all the same for different sites and different combination modes. The dampers are positioned with one in each storey from the first to the third floor. It has no influence on the optimal solution for the low building whether the acceleration factor is taken into account or not as the safety factor is considered. As the force-deformation responses are dependent on the relative velocity and acceleration between each end of these types of devices, the acceleration factor has been considered when the dampers are placed on the structure.

According to the optimal results of MDs shown in Table 5, optimal locations are the same for modes 1, 2, and 3 and same for modes 4, 5, and 6 on sites I and III. For the sites IV, optimal results of modes 1 and 2 are the same and modes 3,4 , and 6 are the same also. The optimal locations are uniform on site II for six combination mode.

\subsubsection{0-Storey Building}

The optimal locations of two types of dampers are shown in Tables 6 and 7. The results indicate that optimal solutions are the same for the combination modes 1 and 2. Meanwhile, 


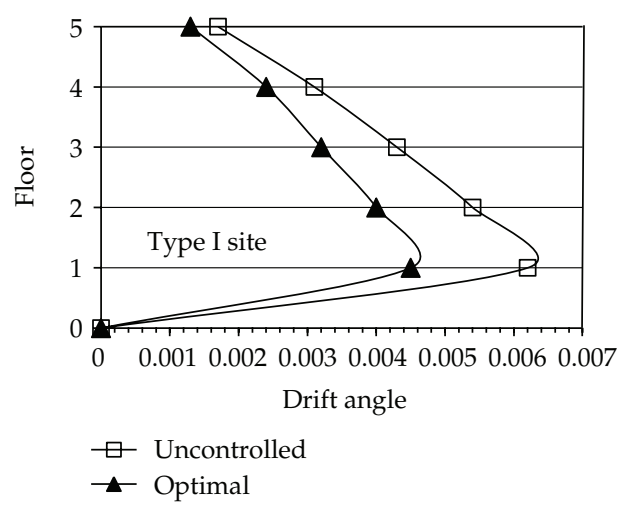

(a)

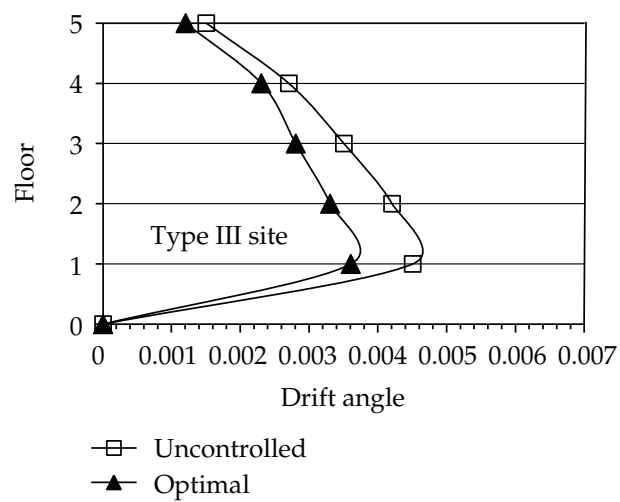

(c)

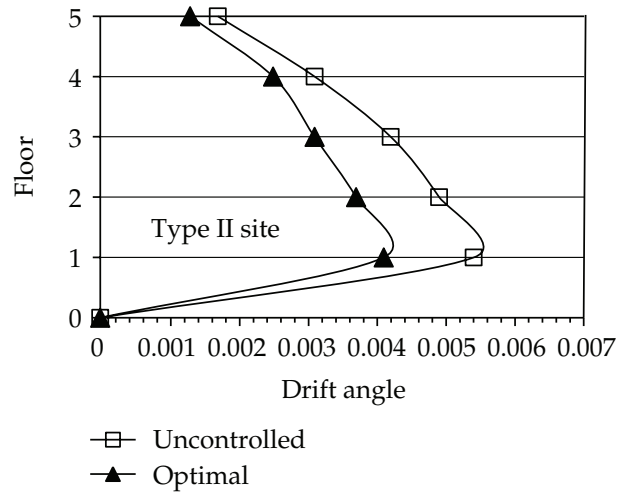

(b)

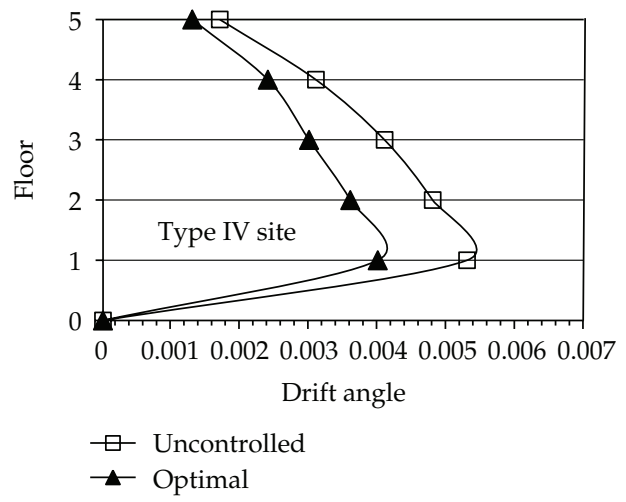

(d)

Figure 5: Envelope diagrams of maximal drift angle for 5-storey structure with VEDs.

when the modes 4 and 5 are adopted respectively, the optimal results for dampers are the same. For the site I, the optimal locations of VEDs are uniform for the modes 1, 2, 3, and 6 with dampers mainly located on top part of the building. When the modes 4 and 5 are adopted, the VEDs are placed on average at the top six floors. The MDs are mainly located in the middle and top of the building on the site I. For the sites II and III, the VEDs are positioned in the middle and top part, while the MDs are located on the bottom and middle of the building. For the site IV, the optimal locations of two types of dampers are uniform for the modes 1 and 2. The optimal results of VEDs using modes 4, 5, and 6 are the same as results of MDs using mode 6 . These results indicate that the appropriate increase in acceleration weight has less effect on the optimal results of velocity-based dampers.

\subsubsection{6-Storey Building}

The optimal locations of two types of dampers on the four soil sites are shown in Tables 8 and 9. The optimal results indicate that optimal locations of VEDs are the same by using the combination modes 1 and 2 for each site condition. For the site I, dampers are mainly located in the middle part of the structure. Considering the sites II and III, dampers are placed on the bottom and middle part. Dampers are positioned in the middle and top part of the building 


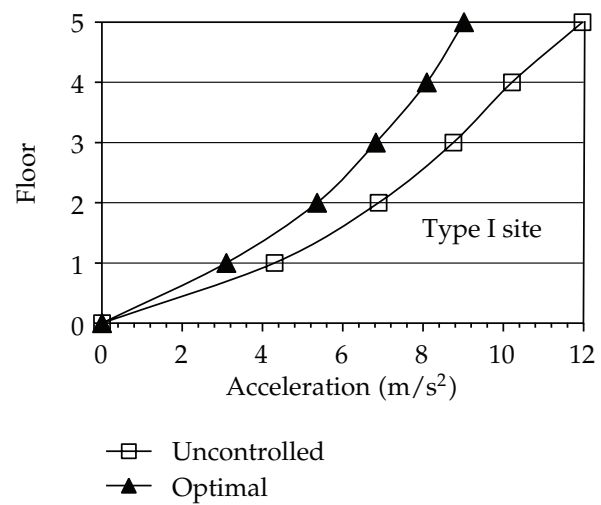

(a)

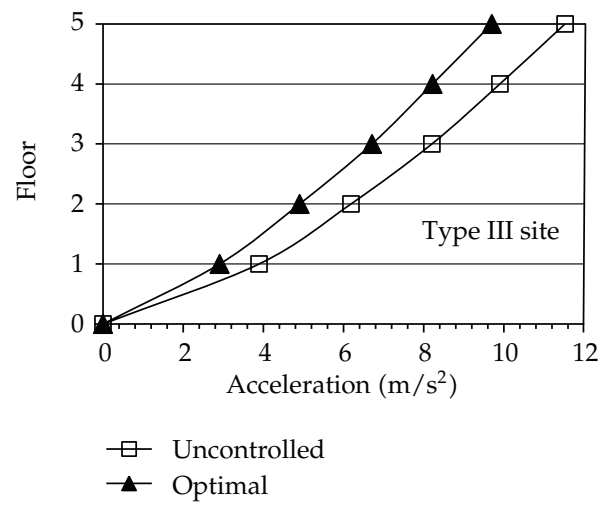

(c)

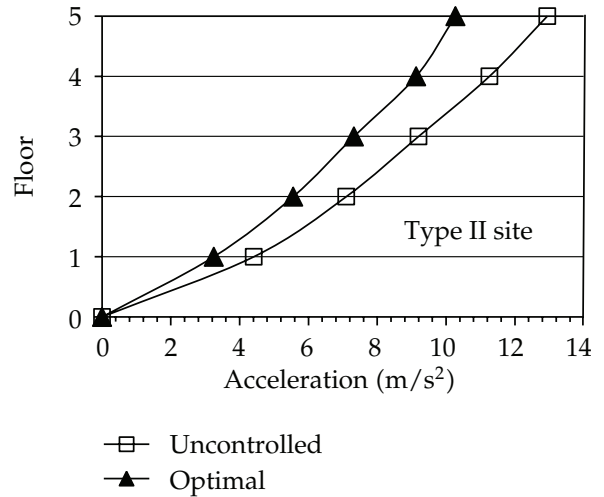

(b)

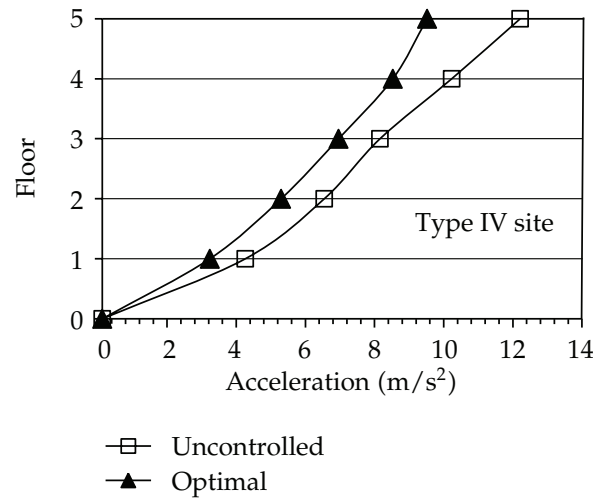

(d)

Figure 6: Envelope diagrams of maximal acceleration for 5-storey structure with VEDs.

on the site IV. These results mean that the acceleration factor has an impact upon the optimal locations for high buildings. As far as the MDs are taken, optimal results are the same for the modes 1 and 2 and same for the modes 4 and 5 only on the site I.

When the dampers are located in structures according to the optimal results with six modes of coefficients combination, the step-by-step time history analysis is utilized to obtain the responses of structures with two types of dampers on the four types of sites, respectively. As the space of the paper is limited, some typical envelope diagrams of three buildings on the different sites are displayed from Figures 4, 5, 6, 7, 8, 9, 10, and 11.

\subsection{Comparisons between Different Combination Modes}

\subsubsection{5-Storey Building}

No comparisons are done because the optimal results of VEDs are all the same for 6 combination modes. In order to compare six modes with one another to decide which one can generate better control effectiveness of structures with optimal locations of MDs, two estimating dimensionless indices are calculated according to formula (3.2) as shown in Table 10. 

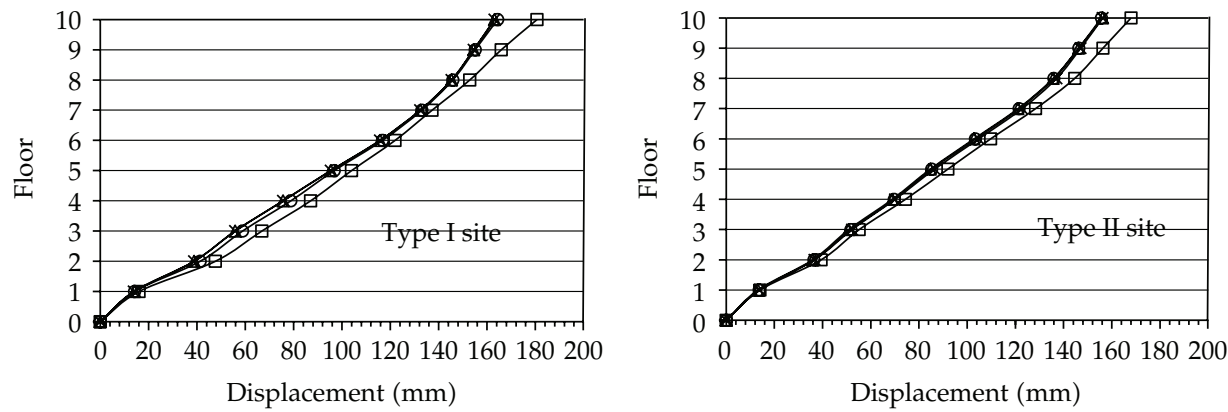

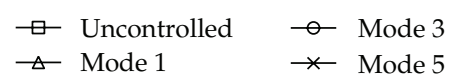

(a)

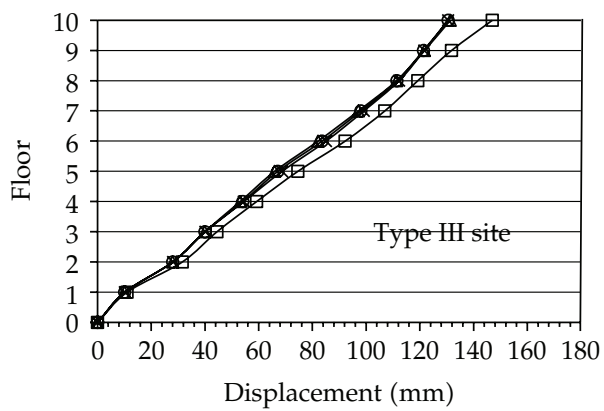

$\begin{array}{ll}\square \text { Uncontrolled } & - \text { Mode } 3 \\ \triangle \text { Mode } 1 & \times \text { Mode } 5\end{array}$

(c)

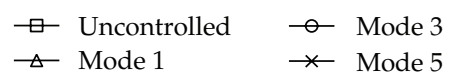

(b)

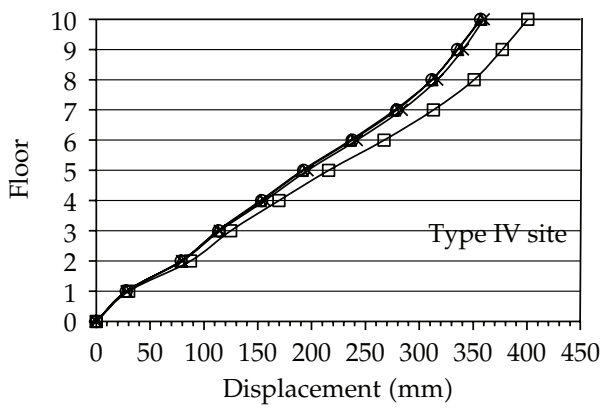

$\begin{array}{ll}\square \text { Uncontrolled } & - \text { Mode } 3 \\ \triangle & \text { Mode } 1\end{array}$

(d)

Figure 7: Envelope diagrams of maximal displacement for 10-storey structure with VEDs.

Table 8: Location optimization of VEDs for 16-storey building.

\begin{tabular}{lccc}
\hline Site & Modes 1 and 2 & Modes 3 and 6 & Modes 4 and 5 \\
\hline I & 235678101112 & $125678101112 /$ & $12356781214 /$ \\
& & 12356781011 & 123568111214 \\
II & 1234567811 & $1234567810 /$ & 5678910141516 \\
& & 123456789 & $134567101113 /$ \\
III & 23456781011 & $12456781011 /$ & 1246710111213 \\
& & 12356781011 & $1210111213141516 /$ \\
IV & 256789101113 & $1234510111416 /$ & 1910111213141516 \\
\hline
\end{tabular}

As far as drift angle is concerned, the control effect is better for modes 1, 2, and 3 on sites I, II, and III. For the site IV, mode 3 can obtain the best optimal results. When the acceleration is taken into consideration, the values of $J_{2}$ are same on site II. For other three sites, the acceleration control is better when modes 5 and 6 are adopted. The acceleration responses of the whole structure may be enlarged when using MDs on sites III and IV. 

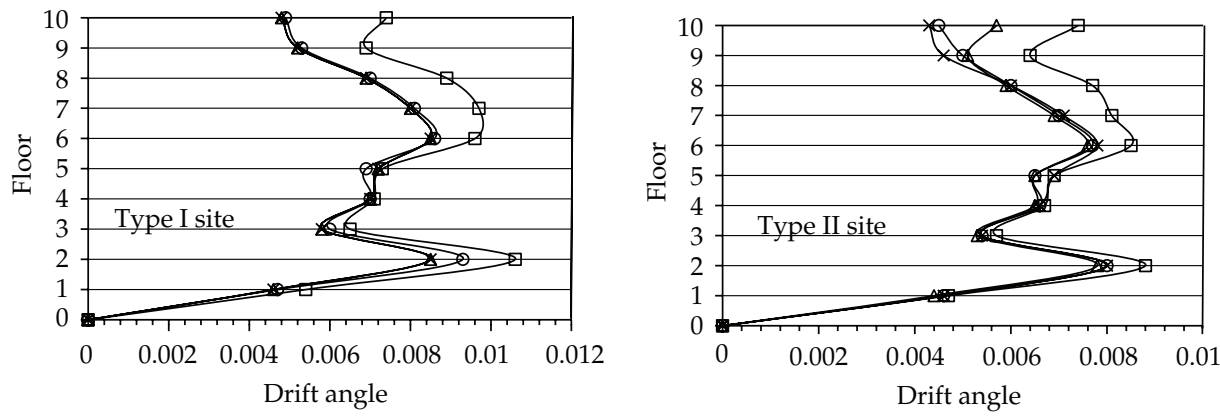

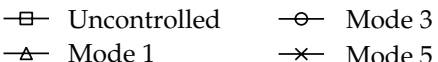

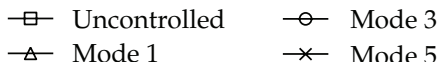

(a)

(b)
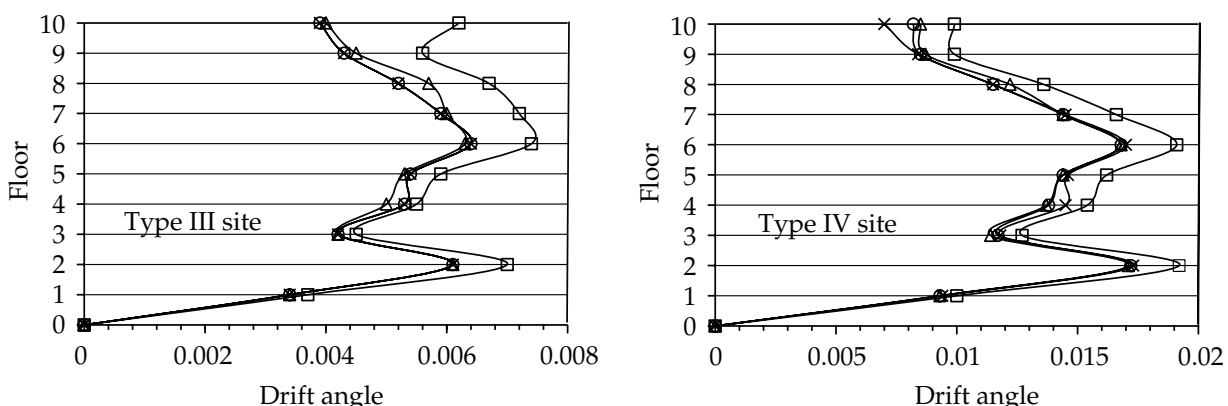

$\square$ Uncontrolled $\quad-$ Mode 3

$\square$ Uncontrolled $\quad-$ Mode 3

(c)

(d)

Figure 8: Envelope diagrams of maximal drift angle for 10-storey structure with VEDs.

Table 9: Location optimization of MDs for 16-storey building.

\begin{tabular}{lccc}
\hline Site & Modes 1 and 2 & Modes 3 and 6 & Modes 4 and 5 \\
\hline I & 12356791011 & $246789101116 /$ & 23467891016 \\
& $156789101112 /$ & 136789101116 & $689101112131416 /$ \\
II & 156789101415 & $14567891014 /$ & 126789131415 \\
& $12345891011 /$ & 34567891015 & $2367810111415 /$ \\
III & 34569101215 & $12567891011 /$ & 123689111516 \\
& $12345671014 /$ & 23567891011 & $234567101115 /$ \\
IV & 1234567810 & $123456101516 /$ & 3457910121314 \\
\hline
\end{tabular}

Table 10: Evaluation indices of objective function for 5-storey structure with MD.

\begin{tabular}{lcccccc}
\hline $\begin{array}{l}\text { Index } \\
\text { site }\end{array}$ & Mode 1 & Mode 3 & Modes 5 and 6 & Mode 1 & Mode 3 & Modes 5 and 6 \\
\hline I & 0.4774 & 0.4774 & 0.4978 & 0.7898 & 0.7898 & 0.7666 \\
II & 0.4814 & 0.4814 & 0.4814 & 0.7664 & 0.7664 & 0.7664 \\
III & 0.4945 & 0.4945 & 0.5101 & 1.0782 & 1.0782 & 0.9577 \\
IV & 0.4790 & 0.4410 & 0.4871 & 1.0449 & 1.0580 & 1.0494 \\
\hline
\end{tabular}




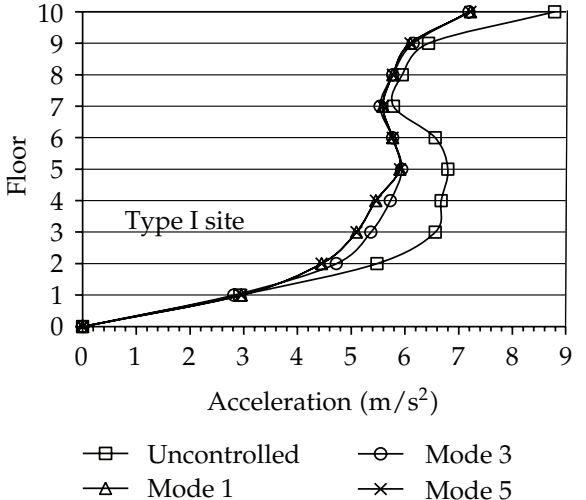

(a)

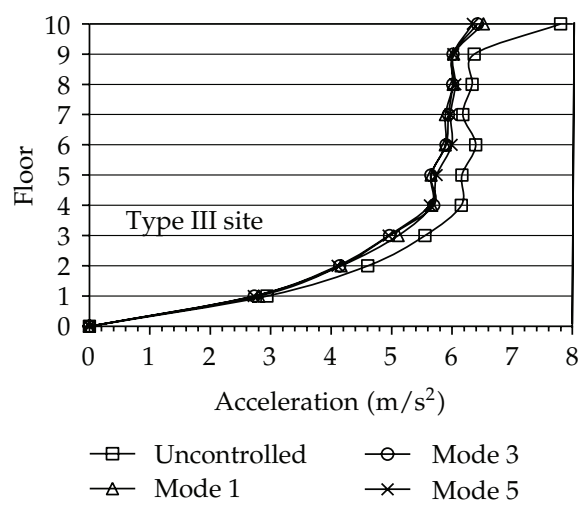

(c)

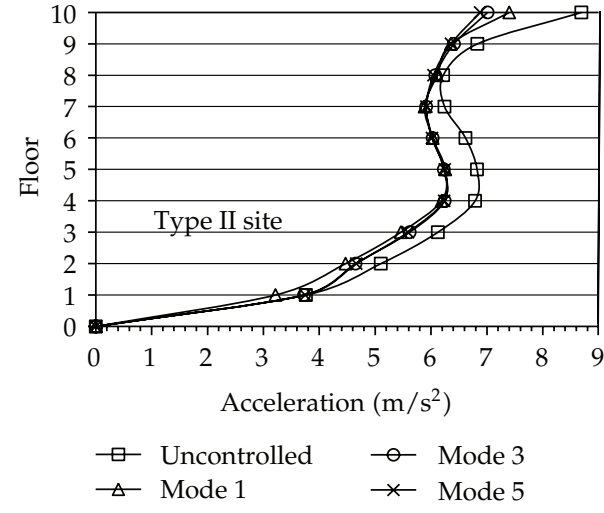

(b)

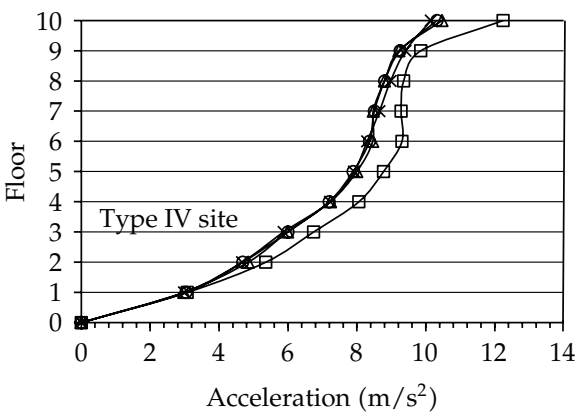

$$
\begin{array}{ll}
\square \text { Uncontrolled } & - \text { Mode } 3 \\
\square \text { Mode } 1 & * \text { Mode } 5
\end{array}
$$

(d)

Figure 9: Envelope diagrams of maximal acceleration for 10-storey structure with VEDs.

\subsubsection{0-Storey Building}

Two estimating indices are calculated as shown in Table 11 for the structure with MDs. The results in Table 11 indicate that the mode 1 is best for the drift angle control on the site I and the value of mode 3 is better than other modes except for the mode 1. As far as acceleration is taken into account, it is obvious that the mode 6 is the best. For the site II, the control effects of drift angle are the best when using modes 3 and 6 while mode 1 is the best for acceleration control. For the site III, mode 3 can obtain the smallest $J_{1}$ value. Meanwhile, the acceleration control effects are better for modes 5 and 3. For the site IV, the results are the same when using modes 3 and 5 which can obtain the best control effects of drift angle and acceleration. According to the above analysis, the optimal objective function should use mode 1 on site I, mode 3 on sites II and III and mode 5 on site IV for intermediate period structure with displacement-based dampers.

Two evaluation indices are calculated as shown in Table 12 for the structure with VEDs. The $J_{1}$ and $J_{2}$ values of modes $1,2,3$, and 6 are the same on site I. The results shown in Table 12 indicate that mode 3 is the best one for drift-angle control on sites I, II, and III while modes 5 and 6 are better on site IV. When the acceleration is taken into consideration, the numerical difference of $J_{2}$ is not obvious. Considering two indices and simple form of 


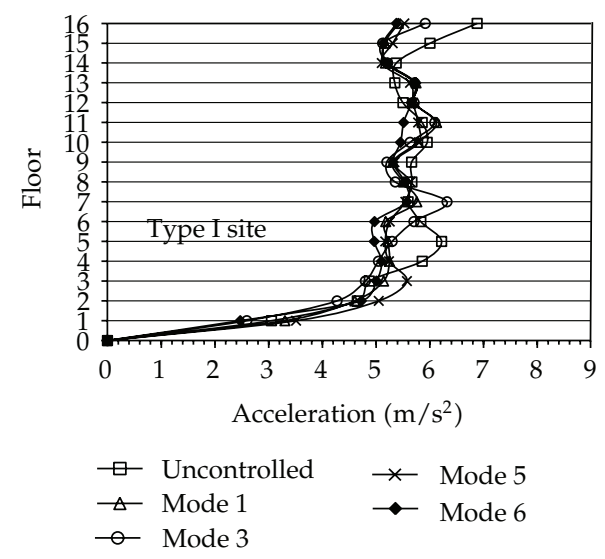

(a)

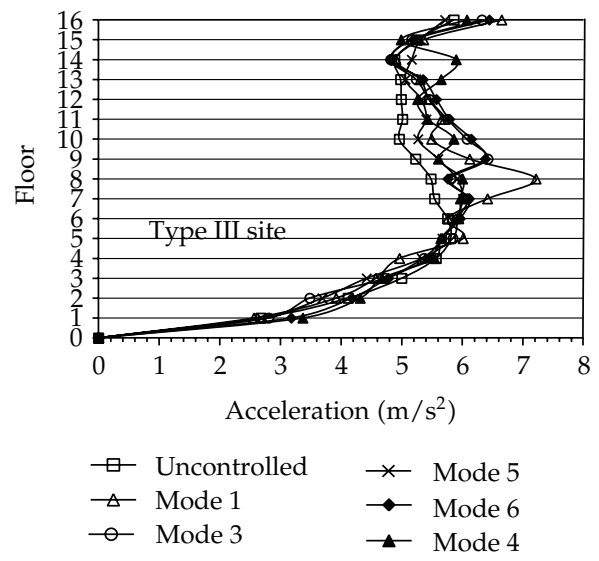

(c)

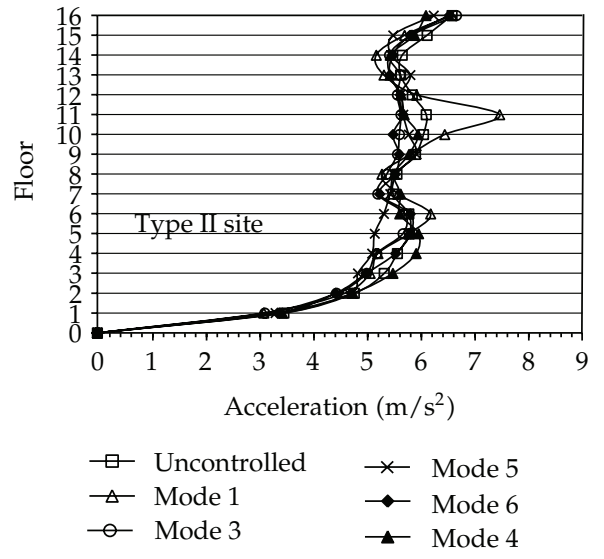

(b)
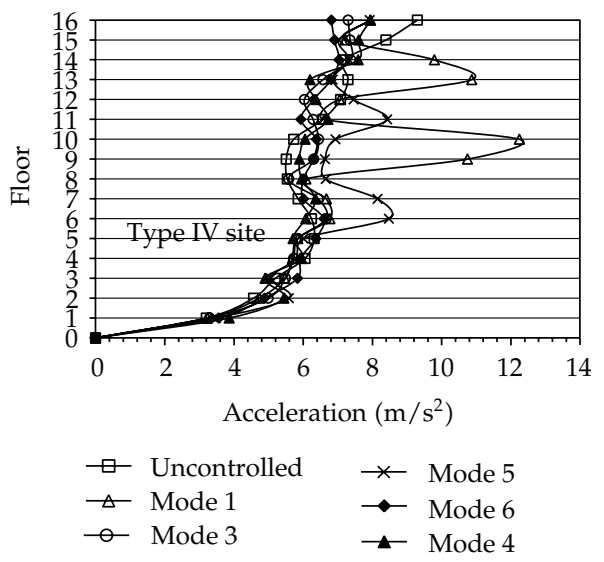

(d)

Figure 10: Envelope diagrams of maximal acceleration for 16-storey structure with MDs.

objective functions, the optimal objective function should use mode 1 on sites I and II, mode 5 on sites III and IV for intermediate period structure with velocity-based dampers.

\subsubsection{6-Storey Building}

The indices $J_{1}$ and $J_{2}$ are calculated for the 16-storey building with MDs shown in Table 13. The results in Table 13 show that the mode 3 is the best for drift angle control on the site I. The mode 6 is the best for acceleration control, while modes 1,2, and 3 are better than other modes except for mode 6 on the site I. For the site II, the control effects of drift angle are the best when using mode 1 , while modes 2 and 5 are better for acceleration control. For the sites III and IV, mode 3 can obtain the smallest $J_{1}$ values, while the acceleration may be enlarged for the structure with the MDs. According to the above analysis, the optimal objective function should use the mode 3 for a long-period structure with the displacement-based dampers which can obtain better control effectiveness for the drift angle. 


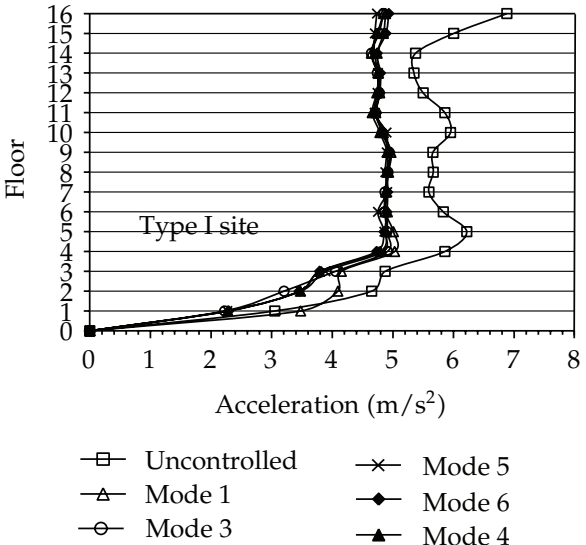

(a)

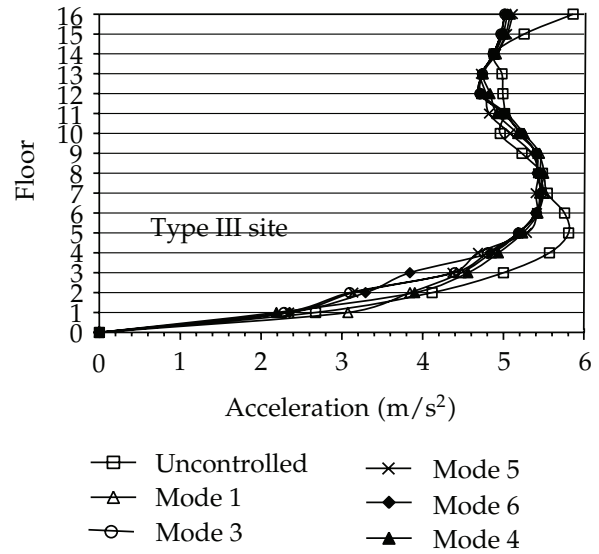

(c)
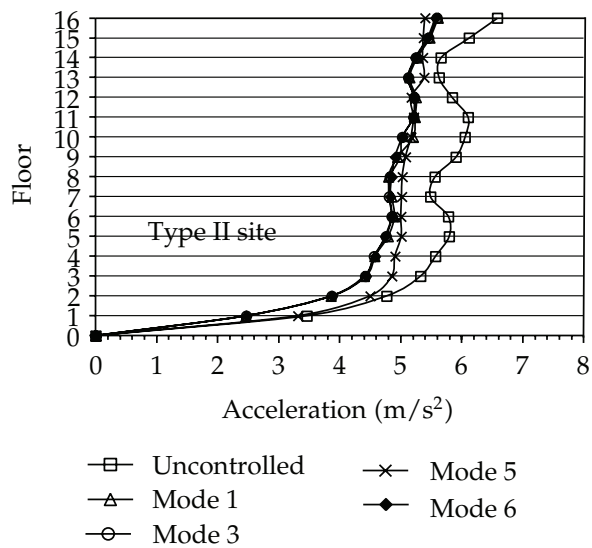

(b)
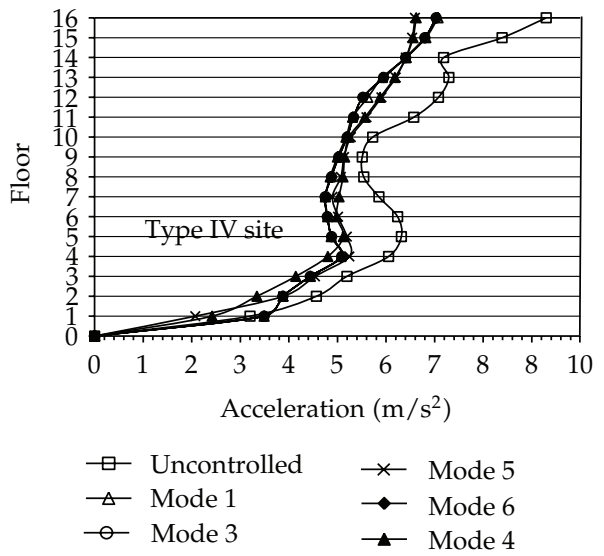

(d)

Figure 11: Envelope diagrams of maximal acceleration for 16-storey structure with VEDs.

Table 11: Evaluation indices of objective function for 10-storey structure with MD.

\begin{tabular}{lcccccccc}
\hline $\begin{array}{l}\text { Index } \\
\text { site }\end{array}$ & Mode 1 & Mode 3 & Mode 5 & Mode 6 & Mode 1 & Mode 3 & Mode 5 & Mode 6 \\
\hline I & 0.6596 & 0.6759 & 0.7028 & 0.6902 & 0.9448 & 0.9333 & 0.9268 & 0.8771 \\
II & 0.7984 & 0.7806 & 0.7928 & 0.7806 & 0.9169 & 0.9287 & 0.9454 & 0.9287 \\
III & 0.6880 & 0.6668 & 0.6709 & 0.6760 & 0.9336 & 0.8905 & 0.8794 & 0.9233 \\
IV & 0.6469 & 0.6419 & 0.6419 & 0.6454 & 0.8991 & 0.8080 & 0.8080 & 0.9077 \\
\hline
\end{tabular}

Table 12: Evaluation indices of objective function for 10-storey structure with VED.

\begin{tabular}{lcccccccc}
\hline $\begin{array}{l}\text { Index } \\
\text { site }\end{array}$ & Mode 1 & Mode 3 & Mode 5 & Mode 6 & Mode 1 & Mode 3 & Mode 5 & Mode 6 \\
\hline I & 0.7164 & 0.7164 & 0.7392 & 0.7164 & 0.7927 & 0.7927 & 0.8048 & 0.7927 \\
II & 0.7696 & 0.7694 & 0.7724 & 0.7724 & 0.8242 & 0.8550 & 0.8506 & 0.8506 \\
III & 0.7246 & 0.7246 & 0.7313 & 0.7248 & 0.8519 & 0.8519 & 0.8439 & 0.8418 \\
IV & 0.7886 & 0.7774 & 0.7748 & 0.7748 & 0.8334 & 0.8269 & 0.8262 & 0.8262 \\
\hline
\end{tabular}


Table 13: Evaluation indices of objective function for 16-storey structure with MD.

\begin{tabular}{lcccccccccccc}
\hline $\begin{array}{l}\text { Index } \\
\text { site }\end{array}$ & M 1 & M 2 & M 3 & M 4 & M 5 & M 6 & M 1 & M 2 & M 3 & M 4 & M 5 & M 6 \\
\hline I & 0.538 & 0.538 & 0.503 & 0.544 & 0.544 & 0.514 & 0.911 & 0.911 & 0.922 & 0.963 & 0.963 & 0.870 \\
II & 0.644 & 0.650 & 0.647 & 0.676 & 0.681 & 0.648 & 0.988 & 0.909 & 0.920 & 0.973 & 0.911 & 0.928 \\
III & 0.637 & 0.619 & 0.593 & 0.607 & 0.599 & 0.612 & 1.133 & 1.169 & 1.111 & 1.154 & 1.034 & 1.161 \\
IV & 0.525 & 0.535 & 0.518 & 0.546 & 0.623 & 0.556 & 1.535 & 1.143 & 0.970 & 1.021 & 1.230 & 1.011 \\
\hline
\end{tabular}

Table 14: Evaluation indices of objective function for 16-storey structure with VED.

\begin{tabular}{lcccccccccccc}
\hline $\begin{array}{l}\text { Index } \\
\text { site }\end{array}$ & M 1 & M 2 & M 3 & M 4 & M 5 & M 6 & M 1 & M 2 & M 3 & M 4 & M 5 & M 6 \\
\hline I & 0.4645 & 0.4645 & 0.4568 & 0.4690 & 0.4680 & 0.4664 & 0.7435 & 0.7435 & 0.6696 & 0.6704 & 0.6671 & 0.6754 \\
II & 0.5606 & 0.5606 & 0.5480 & 0.6063 & 0.6063 & 0.5522 & 0.7287 & 0.7287 & 0.7228 & 0.8009 & 0.8009 & 0.7225 \\
III & 0.5172 & 0.5172 & 0.5130 & 0.5267 & 0.5264 & 0.5189 & 0.9421 & 0.9421 & 0.8773 & 0.9071 & 0.8748 & 0.8724 \\
IV & 0.6165 & 0.6165 & 0.5950 & 0.6192 & 0.6306 & 0.6185 & 0.7235 & 0.7235 & 0.6665 & 0.6880 & 0.7050 & 0.7236 \\
\hline
\end{tabular}

Two indices are calculated for the 16-storey building with VEDs shown in Table 14. The results reveal that the mode 3 is the best for drift-angle control on all of the four four sites. As far as the acceleration control is concerned, mode 5 is best on site I and mode 3 is better than other modes on site I. The values of modes 6 and 3 are better on sites II and III. For the site IV, mode 3 can obtain the smallest $J_{2}$ value. When control of deformation and acceleration are both taken into account, the mode 3 is the most ideal one for long-period structure with velocity-based dampers.

\section{Conclusions}

The optimal objective functions are different for two types of dampers placed on different buildings on different types of sites.

It has no influence on the optimal locations of VEDs for low buildings whether coziness is taken into account or not as the safety factor is considered on four types of sites. As far as displacement-based dampers are taken, the influence of acceleration factor is very small, but acceleration may be enlarged on the sites III and IV. The objective function of velocity-based dampers can be predigested as $\min Z=\theta_{\max } / \theta_{0, \max }$ regardless of the type of site, which has easier form to compute. According to the evaluation indices, the objective function of displacement-based dampers can be taken as $\min Z=\theta_{\max } / \theta_{0, \max }$ on sites I, II, and III while adopting the form $\min Z=0.5\left(\theta_{\max } / \theta_{0, \max }\right)+0.3\left(a_{\max } / a_{0, \max }\right)+0.2\left(u_{\max } / u_{0, \max }\right)$ on site IV.

For intermediate period structures, it is suggested to use $\min Z=\theta_{\max } / \theta_{0, \max }$ as the objective function on site I, $\min Z=0.5\left(\theta_{\max } / \theta_{0, \max }\right)+0.3\left(a_{\max } / a_{0, \max }\right)+0.2\left(u_{\max } / u_{0, \max }\right)$ on sites II, III and $\min Z=a_{\max } / a_{0, \max }$ on site IV for displacement-based dampers. As far as velocity-based dampers are taken, the objective function should be taken as $\min Z=$ $\theta_{\max } / \theta_{0, \max }$ on sites I, II and $\min Z=a_{\max } / a_{0, \max }$ on sites III and IV.

For long-period structures, both safety and amenity should be taken into consideration to obtain better acceleration control. It is suggested to use $\min Z=0.5\left(\theta_{\max } / \theta_{0, \max }\right)+$ $0.3\left(a_{\max } / a_{0, \max }\right)+0.2\left(u_{\max } / u_{0, \max }\right)$ as the objective function of two type dampers regardless of types of sites. 


\section{Acknowledgments}

This research work was jointly supported by the Science Fund for Creative Research Groups of the NSFC (Grant no. 51121005), the National Science Foundation for Distinguished Young Scholars of China (Grant no. 51108064), and the Fundamental Research Funds for the Central Universities. The authors would like to thank the reviewers for their careful reading of the paper and their constructive criticism.

\section{References}

[1] R. T. Haftka and H. M. Adelman, "Selection of actuator locations for static shape control of large space structures by heuristic integer programing," Computers and Structures, vol. 20, no. 1-3, pp. 575-582, 1985.

[2] S. A. Ashour and R. D. Hanson, "Elastic seismic response of buildings with supplemental damping," Tech. Rep. UMCE 87-01, Department of Civil Engineering, University of Michigan, Ann Arbor, Mich, USA, 1987.

[3] R. H. Zhang and T. T. Soong, "Seismic design of viscoelastic dampers for structural applications," Journal of Structural Engineering, ASCE, vol. 118, no. 5, pp. 1375-1392, 1992.

[4] M. Gürgöze and P. C. Müller, "Optimal positioning of dampers in multi-body systems," Journal of Sound and Vibration, vol. 158, no. 3, pp. 517-530, 1992.

[5] H. G. Natke and T. T. Soong, "Topological structural optimization under dynamic loads," in Optimization of Structural systems and Applications, S. Hernandez and C. A. Brebbia, Eds., Computational Mechanics Publications, Southampton, UK, 1993.

[6] M. H. Milman and C. C. Chu, "Optimization methods for passive damper replacement and tuning," Journal of Guidance, Control, and Dynamics, vol. 17, no. 4, pp. 848-856, 1994.

[7] I. Takewaki, “Optimal damper placement for minimum transfer functions,” Earthquake Engineering and Structural Dynamics, vol. 26, no. 11, pp. 1113-1124, 1997.

[8] I. Takewaki, S. Yoshitomi, K. Uetani, and M. Tsuji, "Non-monotonic optimal damper placement via steepest direction search," Earthquake Engineering and Structural Dynamics, vol. 28, pp. 655-670, 1999.

[9] Y. Zhou, Z. D. Xu, and X. S. Deng, "Optimal installation of the dampers in the viscoelastic structures," World Information of Earthquake Engineering, vol. 14, no. 3, pp. 15-20, 1998.

[10] Q. Zhang, W. J. Lou, and Y. Chen, "The objective function and realization of optimal placement for viscoelastic dampers," Industrial Construction, vol. 33, no. 6, pp. 10-13, 2003.

[11] P. Lu, S. Chen, and Y. Zheng, "Artificial intelligence in civil engineering," Mathematical Problems in Engineering, vol. 2013, Article ID 145974, 20 pages, 2013.

[12] S. Y. Chen and Y. F. Li, "Automatic sensor placement for model-based robot vision," IEEE Transactions on Systems, Man, and Cybernetics B, vol. 34, no. 1, pp. 393-408, 2004.

[13] C. Cattani, S. Chen, and G. Aldashev, "Information and modeling in complexity," Mathematical Problems in Engineering, vol. 2012, Article ID 868413, 4 pages, 2012.

[14] M. P. Singh and L. M. Moreschi, "Optimal placement of dampers for passive response control," Earthquake Engineering and Structural Dynamics, vol. 31, no. 4, pp. 955-976, 2002.

[15] L. M. Moreschi and M. P. Singh, "Design of yielding metallic and friction dampers for optimal seismic performance," Earthquake Engineering and Structural Dynamics, vol. 32, no. 8, pp. 1291-1311, 2003.

[16] W. Zheng, S. Yan, and J. H. Mo, "Optimum installation of the MR dampers for the high-rise structures by genetic algorithm," Journal of Shenyang Jianzhu University (Natural Science), vol. 21, no. 6, pp. 606611, 2005.

[17] W. M. Bei and H. N. Li, "Study on the optimal placement of magnetorheological dampers in structural control," Earthquake Resistant Engineering and Retrofitting, vol. 28, no. 3, pp. 73-78, 2006.

[18] K. C. Chang, M. L. Lai, T. T. Soong, D. S. Hao, and Y. C. Yeh, "Seismic behavior and design guidelines for steel frame structures with added viscoelastic damper," NCEER 93-0009, National Center for Earthquake Engineering Research, Buffalo, NY, USA, 1993.

[19] Z. Ming and S. Shudong, The Principle and Application of Genetic Algorithms, National Defense Industry Press, Beijing, China, 1999. 
[20] G. Giardini and T. Kalmár-Nagy, "Genetic algorithm for combinatorial path planning: the subtour problem," Mathematical Problems in Engineering, vol. 2011, Article ID 483643, 31 pages, 2011.

[21] Z. D. Xu, Y. Zhou, and H. T. Zhao, "Optimum design method of the viscoelastic structure," Journal of Xi'an University of Architecture and Technology (Natural Science Edition), vol. 31, no. 3, pp. 246-248, 1999.

[22] S. Chen, Y. Wang, and C. Cattani, "Key issues in modeling of complex 3D structures from video sequences," Mathematical Problems in Engineering, vol. 2012, Article ID 856523, 17 pages, 2012.

[23] S. Chen, W. Huang, C. Cattani, and G. Altieri, "Traffic dynamics on complex networks: a survey," Mathematical Problems in Engineering, vol. 2012, Article ID 732698, 23 pages, 2012.

[24] S. C. Lim, C. H. Eab, K. H. Mak, M. Li, and S. Y. Chen, "Solving linear coupled fractional differential equations by direct operational method and some applications," Mathematical Problems in Engineering, vol. 2012, Article ID 653939, 28 pages, 2012.

[25] S. Y. Chen, J. Zhang, Q. Guan, and S. Liu, "Detection and amendment of shape distortions based on moment invariants for active shape models," IET Image Processing, vol. 5, no. 3, pp. 273-285, 2011.

[26] L. Xie and C. Zhai, "Study on the severest real ground motion for seismic design and analysis," Acta Seismologica Sinica, vol. 25, no. 3, pp. 250-261, 2003. 


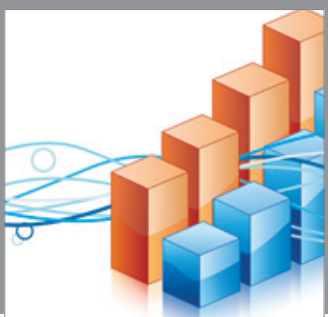

Advances in

Operations Research

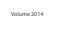

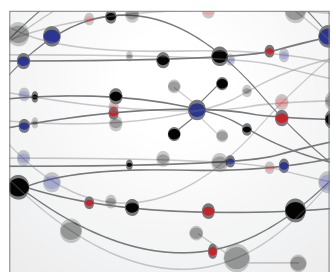

\section{The Scientific} World Journal
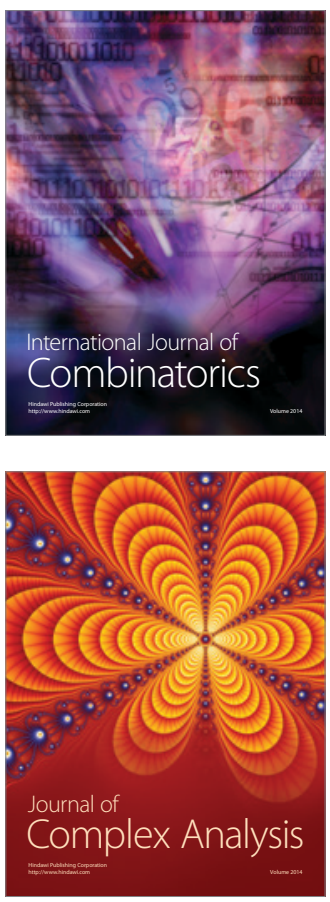

International Journal of

Mathematics and

Mathematical

Sciences
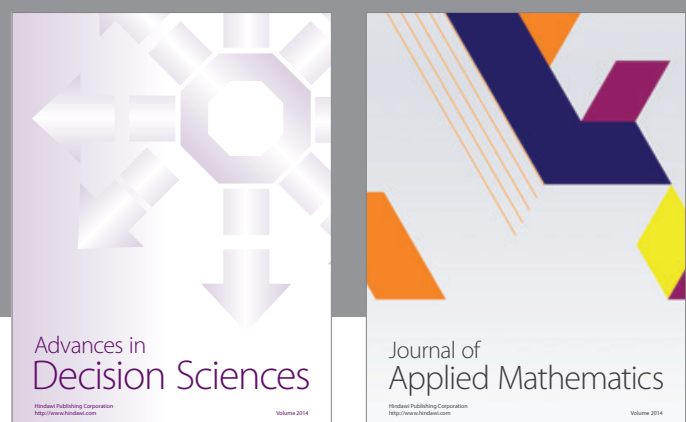

Journal of

Applied Mathematics
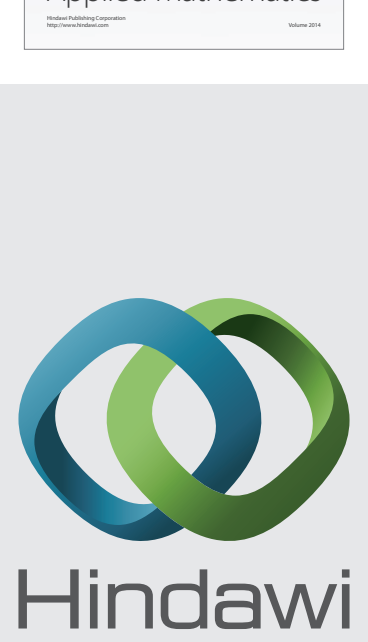

Submit your manuscripts at http://www.hindawi.com
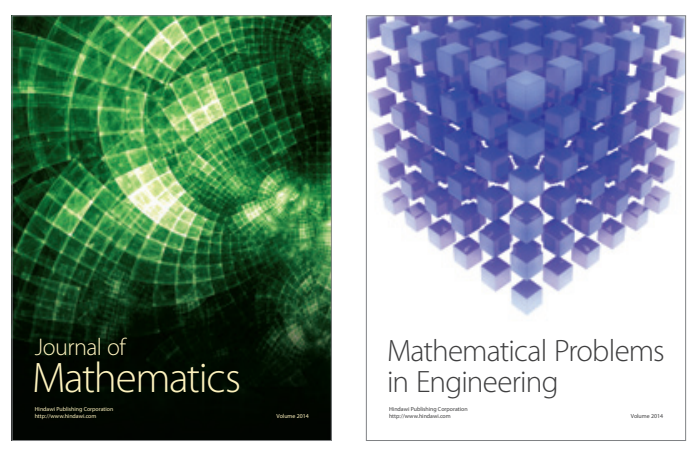

Mathematical Problems in Engineering
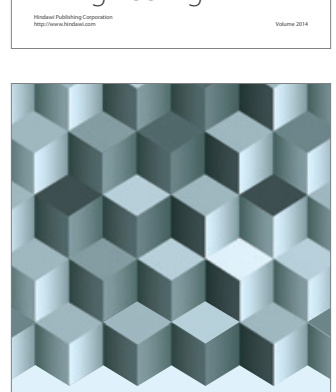

Journal of

Function Spaces
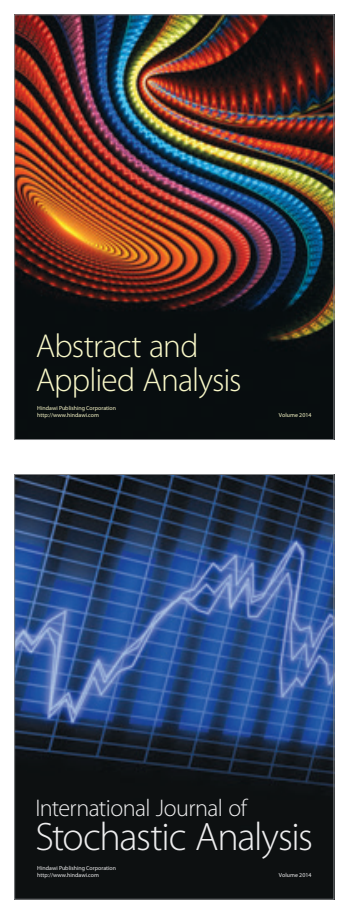

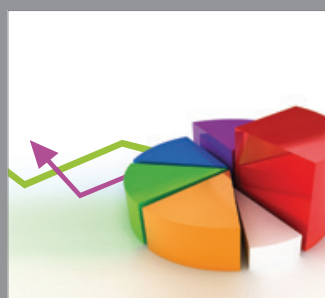

ournal of

Probability and Statistics

Promensencen
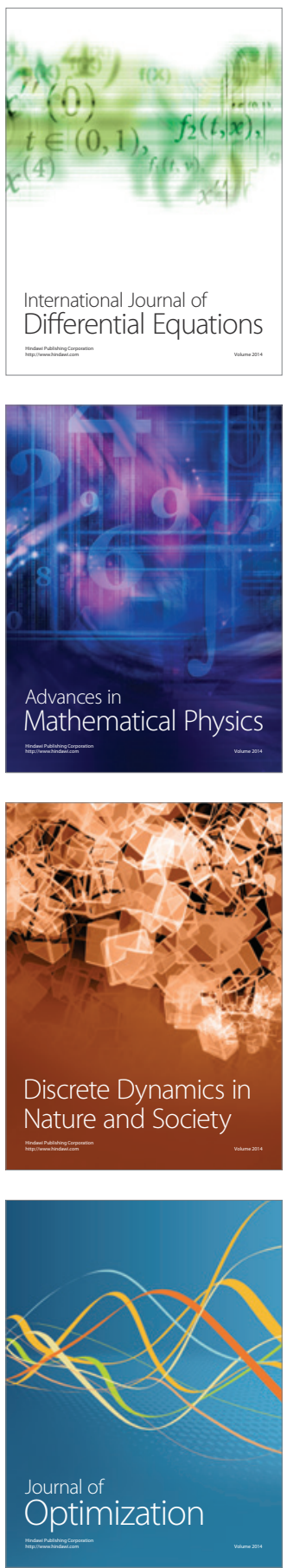